\title{
Glossierung (cf. Leipzig Glossing Rules 2015)
}

$\begin{array}{ll}\text { 1SG } & \text { 1. Person Singular } \\ \text { 2SG } & \text { 2. Person Singular } \\ \text { 3SG } & \text { 3. Person Singular } \\ \text { 1PL } & \text { 1. Person Plural } \\ \text { 2PL } & \text { 2. Person Plural } \\ \text { 3PL } & \text { 3. Person Plural } \\ \text { ACC } & \text { Akkusativ } \\ \text { ADJ } & \text { Adjektiv } \\ \text { ADV } & \text { Adverb } \\ \text { ART.DEF } & \text { definiter Artikel } \\ \text { ART.INDEF } & \text { indefiniter Artikel } \\ \text { COND } & \text { Konditional } \\ \text { CONJ } & \text { Konjunktion } \\ \text { COP } & \text { Kopula } \\ \text { DAT } & \text { Dativ } \\ \text { F } & \text { Femininum } \\ \text { FUT } & \text { Futur } \\ \text { GENERISCH } & \text { generisches Genus } \\ \text { IMP } & \text { Imperativ } \\ \text { IND } & \text { Indikativ } \\ \text { INF } & \text { Infinitiv } \\ \text { KOMPARATIV } & \text { Komparativ } \\ \text { LOCUTION } & \text { Redewendung } \\ \text { M } & \text { Maskulinum } \\ \text { N } & \text { Nomen } \\ \text { NEUTER } & \text { Neutrum } \\ \text { NOM } & \text { Nominativ } \\ \text { NUM } & \text { Numerale } \\ \text { PART } & \text { Partikel } \\ \text { PL } & \text { Plural } \\ \text { PRO } & \text { Pronomen } \\ \text { PRO.DEM } & \text { Demonstrativpronomen } \\ \text { PRO.PERS } & \text { Personalpronomen } \\ \text { PRO.POSS } & \text { Possessivpronomen } \\ \text { PRO.REL } & \text { Relativpronomen } \\ \text { PROG } & \text { Progressiv, Verlaufsform } \\ \text { PROPER NAME } & \text { Eigenname } \\ \text { PRS } & \text { Präsens } \\ \text { PST } & \text { Vergangenheit (past tense) } \\ \text { PTCP } & \\ \text { REFL } & \end{array}$


XIV — Glossierung (cf. Leipzig Glossing Rules 2015)

SG

Singular

SUBJ Subjunktiv

$\mathrm{V}$

Verb

VERBSTAMM Verbstamm 